\title{
The Dark Side of Creativity
}

\author{
Lanlan Liu, Maolin Ye \\ Jinan University, Guangzhou, China \\ Email: Iliulanlan@163.com, maolinye@163.com
}

Received 20 August 2015; accepted 12 September 2015; published 15 September 2015

Copyright (C) 2015 by authors and Scientific Research Publishing Inc.

This work is licensed under the Creative Commons Attribution International License (CC BY).

http://creativecommons.org/licenses/by/4.0/

(c) (i) 0pen Access

\begin{abstract}
Creativity has been regarded as a positive force to promote the development of individuals, organizations and society. However, creativity also has a hidden dark side. In recent years, researchers have proposed the concept of the dark side of creativity and vicious creativity, and the concept focuses on the relationship between creativity and dishonesty. The article combed the researchers on the study of the relationship between creativity and dishonest behavior, creativity by improving individual defending their actions to increase the ability of the dishonest behavior of the individual in a dilemma situation.
\end{abstract}

\section{Keywords}

\section{Creativity, Creativity Thinking, Dishonest}

\section{Introduction}

Creativity is a topic of study across many disciplines and cultures [1]. A consistent, basic definition is that creativity is both new (or different, novel, or original) and appropriate to the task (or useful or relevant). Cultures vary on the value placed on different facets of creativity; eastern cultures particularly consider moral goodness to be a key component [2]. Yet across these many viewpoints, creativity is typically presented as a constructive activity. It is often associated with such positive personal attributes as humor and altruism, positive well-being, better mood and resiliency [3]. Creativity is also often thought to be connected with personal development to such a degree that it is considered both a positive and necessary part of the human experience [4].

Over the past several decades, researchers have explored many of the psychological factors that are considered vital to the creative process and have identified two main components underlying creative performance: divergent thinking and cognitive flexibility. Divergent thinking refers to the ability of individuals to develop original ideas and to envision multiple solutions to a given problem. It involves thinking "without boundaries," or "outside the box" [5]. Cognitive flexibility, by contrast, describes the ability of individuals to restructure knowledge in multiple different ways depending on changing situational demands (i.e., the complexity of the situation). 
Walczyk, Runco, Tripp, and Smith (2008) had come up with solutions to scenarios in which deception would generally lead to successful outcomes. They have found that telling many different lies correlated with divergent fluency (being able to derive many different ideas), which is related to creativity [6]. In addition, creativity is considered beneficial for society in general, as it is a key force in progress and is considered one of the top economic resources. Sternberg (2010) conceptualized wisdom itself as utilizing aspects of creativity and intelligence for the common good by balancing self-interest with the interests of others [7].

However, recently a new theoretical approach has emerged that questions the inherent benevolence of creativity. Cropley, Kaufman, and Cropley (2008) proposed the idea of malevolent creativity, which was creativity that was designed with the intent of harming others [8]. There are other related concepts, such as negative creativity, which emphasize creative actions that have undesirable outcomes, regardless of intent. A wide variety of negative or malevolent acts can be creative. Extreme examples can be disturbing terrorist attacks, such as the innovative preparation and implementation that led to the 9/11 devastation, or other criminal behaviors that use creativity [9].

Similarly, Lee and Dow (2011) found that physical aggression was correlated with the number of creative items linked with violence that a person would offer on a divergent test of creativity [10]. Other examples include commonplace unethical behavior such as lying, committed by people who may value honesty but display unethical behavior for personal gain when given the opportunity [11]. Kaufman, Cropley, Chiera, and White (2012) studied how people perceived acts of varying malevolence. They found that people judged morally complex or ambiguous actions as being more creative than more straightforward actions (either benevolent or malevolent) [12].

Harris, Reiter-Palmon, and Kaufman (2012) found that people with lower emotional intelligence were more likely to have malevolently creative ideas [13]. In addition, creativity has been associated with the broad personality factor of disagreeableness and the related facets of hostility and arrogance. Creativity in the arts has also been associated with being low in conscientiousness, a factor that is associated with the tendency to be irresponsible, prone to take risk, and acting impulsively (Wolfradt \& Pretz, 2001) [14]. But in the realm of creative behavior, there is a necessity for a certain level of sensible risk-taking and impulsivity [15]. It is important to realize that some concepts, such as impulsivity or low conscientiousness, illustrate ways that someone primed to be creative may also be more at risk for demonstrating malevolent creativity since some of the same personality traits overlap with those associated with low integrity.

\section{Creativity and Honest}

\subsection{Creative Personality and Honest}

While the positive aspects of creativity have been praised and tested empirically, it is possible that creative thinking may also have a hidden cost in the form of increased dishonesty when used to resolve ethical dilemmas. Typically operating together, divergent thinking and cognitive flexibility help people find creative solutions to difficult problems, which may be interpreted from different points of view. One such context is provided by ethical dilemmas. Ethical dilemmas often require people to weigh two opposing forces: the desire to maximize self-interest and the desire to maintain a positive view of oneself [16].

Recent research has suggested that individuals tend to resolve this tension through self-serving rationalizations: they behave dishonestly enough to profit from their unethical behavior, but honestly enough to maintain a positive self-concept as honest human beings [17]. When facing the opportunity to behave dishonestly, in fact, most people cheat, if only by a little bit, but not as much as they possibly could [18]. This "minor" cheating can be justified through various means. For instance, one might reason that other people would cheat under the same circumstances or that a little cheating won't hurt anyone.

Both anecdotally and empirically it has been shown that people seem to be more corruptible when they think they can get away with it [17]. What Gino \& Ariely (2012) showed us was that creativity can play an important role in this phenomenon because it allows people to convince themselves they are not actually behaving without integrity as long as they do not overstep a self-designated boundary [11].

However, this level of deception would likely be considered inconsequential "white lies," since these lies only deviate from the truth by approximately $10 \%$. Such self-serving justifications can help individuals convince themselves that their behavior is in fact morally appropriate and, that there is no need to negatively update their moral self-image. As a result, any situation in which there is room to justify potential dishonest or self-interested 
behavior is likely to promote dishonesty [19].

This tendency to behave in a self-interested manner when the behavior in question can be justified was demonstrated years ago in a compelling study by Snyder, Kleck, Strenta, and Mentzer (1979). In the study, participants had to choose one of two rooms in which they would watch a movie with another person and then answer a short survey. In one room, the other person was physically handicapped; in the other room, the person was not. When the movie shown was the same in both rooms, participants were more likely to choose the room where they would sit with the handicapped person rather than the room where they would sit with the non-handicapped partner. But when different movies were projected in the two rooms, most people chose to avoid the stigmatized person since they could easily justify their choices [20].

Similarly, Schweitzer and Hsee (2002) conducted a negotiation study in which sellers of a car provided a buyer with a mileage estimate from a range of possible values and could lie about the estimate. The results indicated that sellers lied to a greater extent when the provided range was wide rather than narrow; they could justify the lie by using their increased uncertainty about the true mileage. Sellers processed the information about the car's mileage in a self-serving manner, allowing them to gain financially. Thus, when individuals can easily generate justifications to reinterpret or rationalize unethical actions they are tempted to engage in, they will be more likely to behave dishonestly for monetary gains as compared to situations in which justifying the behavior is rather difficult [19].

People reach the conclusions they want to reach, "but their ability to do so is constrained by their ability to construct seemingly reasonable justifications for these conclusions". Greater creativity facilitates this self-serving justification process. More specifically, when people are motivated to behave dishonestly so as to benefit financially in a given situation (or to advance their self-interest in other forms), divergent thinking is likely to help them develop original ways to bypass moral rules. Similarly, cognitive flexibility is likely to help them reinterpret available information regarding their own behavior in a self-serving way.

Indeed, as prior research has suggested, creative people are able to perceive and describe what remains hidden from the view of others, and they are also able to develop original ideas and to envision multiple solutions to a given problem [21]. Greater creativity may promote dishonesty in two ways. First, it can help individuals find creative loopholes to solve difficult tasks they are facing, even if that entails crossing ethical boundaries. Second, creativity may help individuals generate various credible reasons to justify their own actions before engaging in them - even when those actions are unethical. Francesca Gino and Dan Ariely (2012) find that greater creativity promotes dishonesty by increasing individuals' ability to justify their unethical actions, both when considering measures of creative personality and when temporarily activating a creative mindset [11].

\subsection{Creative Mindset and Dishonest}

Francesca Gino and Dan Ariely (2012) demonstrate that even when activated temporarily, a creative mindset promotes dishonesty [11]. Several studies have demonstrated that simple primes can automatically activate certain goals and mindsets, which, in turn, influence perception and behavior without explicit conscious awareness [22]. For instance, Fitzsimons, Chartrand, and Fitzsimons (2008) found that participants primed with Apple logos (i.e., the logos of a company commonly associated with creativity and innovation) behaved more creatively on subsequent tasks as compared to participants primed with IBM logos and control participants [23].

One-hundred eleven undergraduate and graduate students from local universities in the Southeastern United States (52 male; Mage $=23.27, \mathrm{SD}=3.32$ ) participated in the study for payment. Participants engaged in three presumably unrelated tasks: a creativity prime (our manipulation) followed by a two-minute filler task, a creativity task (used as a manipulation check), and the matrix task (used to assess dishonest behavior). Participants were randomly assigned to one of two priming conditions: creative mindset vs. control. All participants were asked to construct grammatically correct four-word sentences (e.g., the sky is blue) from a set of five randomly positioned words (e.g., sky, is, the, why, blue). For the participants in the creative-mindset condition, 12 of the 20 sentences included words related to creativity (creative, original, inventiveness, novel, new, innovative, invention, creativity, ingenious, imagination, originality, and ideas), while for the participants in the control condition, no words related to creativity were included. This priming task was followed by a two-minute filler task to distract participants. They measured creativity triggered by the prime using the Duncker candle problem. Next, participants completed the same problem-solving task with the 20 matrices. They assessed cheating on this task by computing the difference between participants' self-reported and actual performance. Finally, participants 
filled out a questionnaire including demographic questions and post-experimental questions assessing their awareness of the priming. In results, the percentage of participants who correctly solved the candle task was larger in the creative-mindset condition than in the control condition suggesting that priming manipulation was effective. The average number of matrices by which participants overstated their performance was greater in the creative-mindset condition than in the control condition. Furthermore, the percentage of participants who overstated their performance was also higher. These results demonstrate that even when activated temporarily, a creative mindset promotes dishonesty.

\section{The Power of Justifications}

Francesca Gino and Dan Ariely (2012) have demonstrated that creativity promotes dishonesty when people face an ethical dilemma and are motivated to behave unethically, both when creativity is measured as an individual difference and when it is temporarily activated through priming. They proposed that creativity promotes dishonesty by increasing people's ability to justify their unethical actions. They test this hypothesis by manipulating a feature of the task participants completed so that they would have more or less room to justify dishonesty. The less room the task provides for justifying cheating, the more moral flexibility individuals will need if they are to behave dishonestly on that task without feeling too guilty about their actions [11].

Their experiment results provide evidence consistent with the hypothesis that creativity promotes dishonesty by increasing individuals' ability to generate reasons to justify their unethical behavior. Creativity is conducive to cheating on those tasks since it enhances moral flexibility. By contrast, on tasks that provide room for justification by design, creativity is less "beneficial" for dishonesty since moral flexibility is not needed to justify cheating. In addition, they have tested that dispositional creativity moderates the relationship between priming a creative mindset and creative performance, as well as the relationship between priming a creative mindset and dishonest behavior [11].

\section{Future Research Orientations}

Over the last several decades, an increasing number of studies have highlighted the importance of creativity for individuals, organizations, and societies. The majority of this work has stressed the potential and real benefits of creative thinking. For instance, research has shown that creative products generate an average return that is significantly higher than that of "common" products [24], and investments in creativity and innovation positively impact organizational performance [25]. Creativity is also beneficial at the individual level, as it helps us manage our daily lives and find creative solutions to both ordinary and difficult problems. But we must highlight the potential unintended consequences of creativity. Greater creativity helps individuals solve difficult tasks across many domains, but creative sparks may lead individuals to take unethical routes when searching for solutions to problems and tasks.

Firstly, future research could investigate whether creativity would lead people to act in ways that satisfy their selfish, short-term desires rather than their higher goals when facing other types of self-control dilemmas, such as eating a slice of chocolate cake when trying to lose weight.

Secondly, future research could also further examine whether creativity influences individuals' motivations to behave dishonestly as well as their ability to justify self-serving actions.

Thirdly, future work could also examine how creativity may lead to different consequences when people face ethical dilemmas if they are not tempted by the possibility of behaving dishonestly to earn more money.

Finally, future research could investigate the boundary conditions of the effects observed in our studies and examine how people and organizations can foster creativity and benefit from individuals' creative sparks while avoiding unintended evil solutions. Similarly, future work could study the effects of creativity in groups and manipulate the level of competitiveness or cooperation within a group to examine whether promoting a climate of cooperation can reduce the effects of creativity on dishonest behavior.

\section{References}

[1] Kaufman, J.C. and Sternberg, R.J. (2006) The International Handbook of Creativity. Cambridge University Press, New York. http://dx.doi.org/10.1017/CBO9780511818240

[2] Niu, W. and Sternberg, R.J. (2002) Contemporary Studies on the Concept of Creativity: The East and the West. Jour- 
nal of Creative Behavior, 36, 269-288. http://dx.doi.org/10.1002/j.2162-6057.2002.tb01069.x

[3] Amabile, T.M., Barsade, S.G., Mueller, J.S. and Staw, B. (2005) Affect and Creativity at Work. Administrative Science Quarterly, 50, 367-403. http://dx.doi.org/10.2189/asqu.2005.50.3.367

[4] Richards, R. (2007) Everyday Creativity and New Views of Human Nature: Psychological, Social, and Spiritual Perspectives. American Psychological Association, Washington DC. http://dx.doi.org/10.1037/11595-000

[5] Thompson, L. (2008) Making the Team. 3rd Edition, Pearson Education, Inc., Upper Saddle River.

[6] Walczyk, J.J., Runco, M.A., Tripp, S.M. and Smith, C.E. (2008) The Creativity of Lying: Divergent Thinking and Ideational Correlates of the Resolution of Social Dilemmas. Creativity Research Journal, 20, 328-342. http://dx.doi.org/10.1080/10400410802355152

[7] Sternberg, R.J. (2010) The Dark Side of Creativity and How to Combat It. Cambridge University Press, New York. http://dx.doi.org/10.1017/cbo9780511761225.017

[8] Cropley, D.H., Kaufman, J.C. and Cropley, A.J. (2008) Malevolent Creativity: A Functional Model of Creativity in Terrorism and Crime. Creativity Research Journal, 20, 105-115. http://dx.doi.org/10.1080/10400410802059424

[9] Eisenman, R. (1999) Creative Prisoners: Do They Exist? Creativity Research Journal, 12, 205-210. http://dx.doi.org/10.1207/s15326934crj1203 5

[10] Lee, S.A. and Dow, G.T. (2011) Malevolent Creativity: Does Personality Influence Malicious Divergent Thinking? Creativity Research Journal, 23, 73-82. http://dx.doi.org/10.1080/10400419.2011.571179

[11] Gino, F. and Ariely, D. (2012) The Dark Side of Creativity: Original Thinkers Can Be More Dishonest. Journal of Personality and Social Psychology, 3, 445-459. http://dx.doi.org/10.1037/a0026406

[12] Kaufman, J.C., Cropley, D.H., Chiera, B.A. and White, A.E. (2012) Is Hannibal Lecter Creative? How We Evaluate the Creativity of Different Levels of Malevolence. Manuscript Submitted for Publication.

[13] Harris, D.J., Reiter-Palmon, R. and Kaufman, J.C. (2012) The Effect of Emotional Intelligence and Task Type on Malevolent Creativity. Manuscript Submitted for Publication.

[14] Wolfradt, U. and Pretz, J.E. (2001) Individual Differences in Creativity: Personality, Story Writing, and Hobbies. European Journal of Personality, 15, 297-310. http://dx.doi.org/10.1002/per.409

[15] Friedman, R.S. and Förster, J. (2001) The Effects of Promotion and Prevention Cues on Creativity. Journal of Personality and Social Psychology, 81, 1001-1013. http://dx.doi.org/10.1037/0022-3514.81.6.1001

[16] Gino, F., Ayal, S. and Ariely, D. (2009) Contagion and Differentiation in Unethical Behavior: The Effect of One Bad Apple on the Barrel. Psychological Science, 20, 393-398. http://dx.doi.org/10.1111/j.1467-9280.2009.02306.x

[17] Mazar, N., Amir, O. and Ariely, D. (2008) The Dishonesty of Honest People: A Theory of Self Concept Maintenance. Journal of Marketing Research, 45, 633-644. http://dx.doi.org/10.1509/jmkr.45.6.633

[18] Ayal, S. and Gino, F. (2011) Honest Rationales for Dishonest Behavior. In: Mikulincer, M. and Shaver, P.R., Eds., The Social Psychology of Morality: Exploring the Causes of Good and Evil, American Psychological Association, Washington DC, 149-166.

[19] Schweitzer, M.E. and Hsee, C.K. (2002) Stretching the Truth: Elastic Justification and Motivated Communication of Uncertain Information. The Journal of Risk and Uncertainty, 25, 185-201. http://dx.doi.org/10.1023/A:1020647814263

[20] Snyder, M.L., Kleck, R.E., Strenta, A. and Mentzer, S.J. (1979) Avoidance of the Handicapped: An Attributional Ambiguity Analysis. Journal of Personality and Social Psychology, 12, 2297-2306. http://dx.doi.org/10.1037/0022-3514.37.12.2297

[21] Carson, S.H., Peterson, J.B. and Higgins, D.M. (2003) Decreased Latent Inhibition Is Associated with Increased Creative Achievement in High-Functioning Individuals. Journal of Personality and Social Psychology, 85, 499-506. http://dx.doi.org/10.1037/0022-3514.85.3.499

[22] Chartrand, T.L. and Bargh, J.A. (1996) Automatic Activation of Social Information Processing Goals: Nonconscious Priming Reproduces Effects of Explicit Conscious Instructions. Journal of Personality and Social Psychology, 71, 464478. http://dx.doi.org/10.1037/0022-3514.71.3.464

[23] Fitzsimons, G.M., Chartrand, T.L. and Fitzsimons, G.J. (2008) Automatic Effects of Brand Exposure on Motivated Behavior: How Apple Makes You “Think Different”. Journal of Consumer Research, 35, 21-35. http://dx.doi.org/10.1086/527269

[24] Horibe, F. (2001) Creating the Innovation Culture: Leveraging Visionaries, Dissenters and Other Useful Troublemakers in Your Organization. John Wiley \& Sons, New York.

[25] Lev, B. (2004) Sharpening the Intangible Edge. Harvard Business Review, June, 109-116. 